\title{
AUTOLESIONES EN LA ADOLESCENCIA: SIGNIFICADOS, PERSPECTIVAS Y PROSPECCIÓN PARA SU ABORDAJE TERAPÉUTICO
}

\section{SELF-HARM IN ADOLESCENCE: MEANINGS, PERSPECTIVES AND PROSPECTING FOR HIS THERAPEUTIC APPROACH}

\section{Teresa Sánchez-Sánchez}

Terapeuta Psicoanalítica.

Profesora titular de la Facultad de Psicología y en el Máster Universitario de Psicología General Sanitaria. Universidad Pontificia de Salamanca, España.

Cómo referenciar este artículo/How to reference this article:

Sánchez-Sánchez, T.(2018). Autolesiones en la adolescencia: significados, perspectivas y prospección para su abordaje terapéutico. Revista de Psicoterapia, 29(110), 185-209.

\begin{abstract}
Resumen
Se presenta una aproximación epidemiológica, clínica y hermenéutica al fenómeno de las autolesiones adolescentes. Fenómeno casi viral que ha merecido una profusa investigación en otros países, pero escasa en España. El problema de investigación es la comprensión de las dimensiones reales de una manifestación clínica compleja, tal como ha sido enfocada y analizada por los autores más destacados, sobre todo de los últimos veinte años. Comenzamos con una descripción detallada y específica de las Autolesiones Deliberadas No Suicidas, discriminándolas de otros cuadros clínicos o manifestaciones corporales que poseen otras intenciones expresivas e ideológicas. Seguidamente se exponen los tipos y variantes de Conductas Autolesivas (CAL) y pormenorizamos la epidemiología y los significados psíquicos de las mismas. Se prosigue con el análisis de las motivaciones y los factores psicológicos que más frecuentemente se refieren en los centros de salud y terapéuticos, observando éstas desde distintas perspectivas teóricas procedentes de modelos hermenéuticos solventes. El trabajo avanza exponiendo las principales comorbilidades que presentan las autolesiones adolescentes, su yuxtaposición con trastornos clínicos frecuentes en este periodo vital (reacciones al maltrato y al abuso sexual, a experiencias traumáticas, intentos de suicidio, Trastornos de conducta alimentaria, abuso de sustancias, Trastorno Límite, TDAH, estrés...). Se proponen y sopesan las perspectivas y valoraciones clínicas que han atendido este fenómeno (con sus respectivas proyecciones y prospecciones terapéuticas): autorregulación emocional, traumatolisis, búsqueda de identidad, mentalización, expresión vital disfuncional... Finalmente, se aportan algunas líneas de desarrollo futuras de posible valor para la investigación y la terapéutica de esta 'práctica' tan preocupante entre la población clínica y no-clínica de las jóvenes generaciones.
\end{abstract}

\footnotetext{
Fecha de recepción v1: 22 Dic 2017. Fecha de recepción v2: 23 Ene 2018. Fecha de aceptación: 4 May 2018 Correspondencia sobre este artículo:

E-mail: tsanchezsa@upsa.es

Dirección postal: Universidad Pontificia de Salamanca, Calle Compañía, 5, 37002, Salamanca, España 
El propósito esencial es, por tanto, ofrecer un estado de la cuestión actualizado y completo de los aspectos etiopatogénicos, sintomáticos y otras variables contingentes a su presentación clínica para que sirva como una primera guía aproximativa a los terapeutas que hayan de abordar adolescentes con esta preocupante manifestación del malestar psicológico.

Palabras clave: Autolesiones, Clínica, Epidemiología, Motivaciones, Modelos clínicos, Terapia.

\begin{abstract}
Is Presented a study that is an epidemiological, clinical and hermeneutical approach to the phenomenon of adolescent self-harm. It is almost a viral phenomenon that has deserved a profuse investigation in other countries but scarce in Spain. Investigation's problem is the understanding of the real dimensions of a complex clinical manifestation, as it has been focused and analysed by the most outstanding authors, especially in the last twenty years. It begins with a detailed and specific description of Deliberate NonSuicidal Self-injuries, discriminating them from other clinical pictures or corporal manifestations that have other expressive and ideological intentions. Next, the types and variants of Self-contingent Behaviors are exposed and we detail the epidemiology and the psychic meanings of them. We show the analysis of the motivations and psychological factors most frequently referred to in health and therapeutic centers, observing these from different theoretical perspectives from solvent hermeneutic models. The text progresses exposing the main comorbidities presented by adolescent self-harm, their juxtaposition with frequent clinical disorders in this vital period (abuse and sexual abuse reactions, traumatic experiences, suicide attempts, eating disorder, substance abuse, boundary disorder, attention deficiency hyperactivity disorder, stress...). They propose and balance the perspectives and clinical evaluations that have taken care of this phenomenon (with their respective projections and therapeutic prospects): emotional self-regulation, traumatolysis, identity search, mentalization, dysfunctional vital expression ... Finally, we present some lines of future development of possible value for research and the therapy of this 'practice' of concern among the clinical and nonclinical population of the young generations.

The essential purpose is, therefore, to offer an up-to-date and complete status of the etiopathogenic, symptomatic and other contingent variables to its clinical presentation so that is useful as a first approximate guide to therapists who have to approach adolescents with this worrying manifestation of psychological distress.
\end{abstract}

Keywords: Self-harm, Clinic, Epidemiology, Motivations, Clinical models, Therapy 


\section{Introducción}

Con una figura literaria tan expresionista como la que encabeza el titulillo ("un grito de sangre") no se anuncia una película gore, sino el desarrollo de una hermenéutica de las autolesiones adolescentes a la luz de las investigaciones y análisis documentados. Procederemos a un análisis de los significados que los propios adolescentes atribuyen a la razón de ser de los daños que se autoinfligen, sopesaremos las perspectivas desde las que se abordan y plantearemos un apunte prospectivo sobre un problema que ha merecido calificativos tales como "epidemia secreta", "epidemia silenciosa", "suicidio inacabado", "parasuicidio modal juvenil", etc.

\section{Estado de la cuestión}

Vamos en lo sucesivo a identificar las Conductas de Autolesión (CAL) con las conductas que ocasionan de forma deliberada e intencional daños al propio cuerpo pero que carecen de propósito suicida, tal como acotaron Chapman, Gratz y Brown (2006). Los límites del concepto todavía son confusos y su ambigüedad comienza siendo terminológica, dado que según las épocas, los lenguajes de referencia y hasta los países, se han usado preferentemente términos como "suicidio focal" (Menninger, 1938), "parasuicidio"(Kreitman, 1969, 1977), "síndrome de autolesión deliberada" (deliberate self-harm, DSH) (Favazza, 1989, 1998; Morgan, 1979), "autolesión no suicida" (non suicidal self injury, NSSI, o ISNS) (APA, DSM V, 2013), "autoagresión sin propósito suicida", "masoquismo incompleto", "automutilación", "auto-sabotaje" y así hasta 28 etiquetas (González-Suárez, Vasco-Hurtado y Nieto-Betancurt, 2016; Rodríguez Pulido y Delgado Bueno, 1994; Rodríguez Pulido y González de Rivera, 2003) que, lejos de aclarar, han sembrado confusión entre los clínicos porque mezclan conceptos y síntomas que son dispares entre sí. A este babelismo terminológico y conceptual se ha sumado el hecho de que, durante décadas, se consideraba que los daños causados por consumo de sustancias tóxicas y los trastornos en la ingesta, el autoenvenenamiento y conductas rituales religiosas o artísticas (como el body art, entre otros) también eran formas de autolesión. Paulatinamente, la farragosa densidad del bosque conceptual se ha ido clarificando hasta alcanzar un acuerdo unánime en la comunidad médico-psicológica y asistencial, delimitando sus contornos y excluyendo aquellas manifestaciones autolesivas que, aunque causen daños corporales, están revestidas de un significado o halo cultural o religioso (tatuajes, pendientes, incisiones, pinchos, flagelaciones, etc). Así pues, adoptamos el siguiente criterio:

Autolesión impulsiva sin intención suicida (que) corresponde a un acto deliberado y en general recurrente de hacer daño al propio cuerpo sin la ayuda de otra persona, de manera lo suficientemente severa como para ocasionar lesiones en los tejidos corporales y generar hematomas, fracturas, cicatrices o marcas (LunaMontaño, 2012, p. 5).

En los vademécum nosológicos descriptivos e impersonales, del estilo del 
CIE-10 (OMS, 1992) o DSM V (2013), muy discutidos en ciertos sectores clínicos, pero que son ineludible referencia en el diagnóstico, se apuntan otros marcadores que conviene valorar:

(La conducta autolesiva se realiza) con la expectativa de que la lesión solo conllevará un daño físico leve o moderado. Además, ésta debe realizarse para aliviar un sentimiento o estado cognitivo negativo, para resolver una dificultad interpersonal, o para inducir un estado de sentimientos negativos. (APA. DSM V, 2013).

\section{1. ¿Qué excluyen las autolesiones deliberadas no suicidas?}

Descartando las 'transgresiones corporales' (Luna-Montaño, 2012) derivadas del intento de autocorrección que ejecute el sujeto aquejado de Trastorno Dismorfofóbico, las prácticas con propósito estético(Sanders, 2008), reconstructivo o reparador, dentro de las cuales sobresalen por su exotismo y excentricidad las reconstrucciones del virgo o el blanqueamiento anal; descartando igualmente las cirugías plásticas posquirúrgicas subsiguientes a desgarros traumáticos de los tejidos o huesos, a mastectomías, amputaciones y extirpaciones tumorales, etc; descartando igualmente las marcas carcelarias o identitarias impuestas por la pertenencia a bandas o grupos contraculturales como los presidiarios (branding) (Hernández-Jiménez, 2010); descartando las mutilaciones culturalmente bendecidas por ciertas creencias o cultos en algunos países (infibulación o ablación genital); excluyendo igualmente las prácticas ligadas a expresiones parafílicas sadomasoquistas; descartando la apotemnofilia, trastorno que juega en otra liga de trastornos neurológicos (Ramachandrán, 2012), y desestimando los daños autoinfligidos como consecuencia de problemas del desarrollo (autismo, discapacidades cognitivas graves), que tendrán un componente estereotipado (Morán, 1999; Paula y Artigas, 2016), nos quedamos con el núcleo duro de lo que se considera clínicamente una Autolesión deliberada, impulsiva, intencional y no suicida. Ésta es la que centra este trabajo y ésta es la que se ha solapado y ocultado tras otros diagnósticos psicopatológicos, o la que ha sido banalizada bajo el disfraz de "cosas de la edad", un "mal momento", o un "impulso tonto y sin importancia para llamar la atención". Es hora de prestar atención. O, como en su día dijo Charcot, es hora de llegar y permanecer, porque investigar y comprender es curar.

\section{Figuras del daño y el dolor}

Aunque entre las autolesiones deliberadas, impulsivas, intencionales y no suicidas (CAL), las modalidades más frecuentes son los cortes, las quemaduras y los golpes, y a tal fin, varios foros de Internet ofrecen soporte para estas tres opciones, otras prácticas han de registrarse igualmente: inserción de objetos dentro del cuerpo (self-embedding) (Luna-Montaño, 2012), escoriaciones, raspaduras, arañazos, introducción o aspiración de objetos extraños a través de los orificios corporales, automutilación de zonas blandas, enucleación de los ojos y hasta autocanibalismo. Nader y Boehme (2003) enunciaban variantes que aparecen 
cotidianamente en población no clínica, que incluso suelen atribuirse a torpeza motriz, manías, descuido o tendencia a la accidentalidad: arrancarse costras epidérmicas, rascado intenso o excesivo, onicofagia pertinaz hasta provocarse sangrado en las uñas o devorar cutículas y pieles, tricotilomanía, caerse por las escaleras, golpear los puños, propinarse descargas eléctricas, pequeñas asfixias (autosofocación), torniquetes, etc. La clasificación publicada por Ulloa, Contreras, Paniagua y Figueroa (2013) marca una prevalencia indiscutible de los cortes con cuchillas, cuchillos, tijeras o alambres entre las mujeres y de las prácticas temerarias de las que derivan magulladuras, hematomas, contusiones y fracturas entre los hombres.

El compendio recogido y clasificado por Favazza $(1989,1998)$ pone ante los ojos 4 grandes grupos: CAL mayores (castraciones, amputaciones, enucleación), CAL estereotípicas (tales como mericismo, mordeduras, golpes contra superficies duras), CAL compulsivas (escoriaciones, tattoo reiterados, exfoliaciones y escoriaciones) y CAL impulsivas (cortes en la piel, quemaduras, golpes). El "cutting" y el "burning" tienen nombre propio, como si de una práctica deportiva (surfing, puenting, etc) o de una forma de "customización" del cuerpo se tratara, pero las cachetadas, la precipitación desde alturas, los pellizcos con o sin ayuda de otras herramientas (pinzas, llaves, etc) son también frecuentes.

\section{Epidemiología del trastorno}

La práctica de autolesiones deliberadas no letales se ha convertido en un problema de salud pública en todo el mundo, si bien ciertos países-sobre todo Reino Unido- son más conscientes de la magnitud de la 'epidemia cutting' y lanzan mensajes de advertencia y promueven acciones preventivas y/o reductoras de los escandalosos porcentajes de consultas relacionadas con esta causa. Se reportan unas 142.000 consultas al año motivadas por este problema en Escocia e Inglaterra (Pellegrini, 2016). Por ello, la Mental Health Foundation y la Camelot Foundation van a crear centros de formación y concienciación, así como webs de referencia, para los propios adolescentes británicos y el personal que trabaje con ellos. De la amplísima muestra compuesta por 1.171 adolescentes, de entre 12 y 16 años, alumnos de E.S.O. en Barcelona, los resultados concluyeron que el 11,4\% del grupo estudiado había tenido en los últimos 12 meses conductas autolesivas y el 12,5\% ideación suicida, alcanzando su pico más alto en torno a los 16 años. La relación entre CAL e Ideación Suicida (IS) es de un 58\% (Kirchner, Ferrer, Forns y Zanini, 2011). Ratificando estos datos, las cifras reportadas por otros estudios realizados en Canadá, EE.UU, Finlandia o Japón, arrojan cifras similares, pese a estar en latitudes y pertenecer a culturas tan dispares (Albores-Gallo y Méndez-Gallo, 2014; Holm y Severinsson, 2010; Klonsky, 2011; Rodríguez y Guerrero, 2005).

En España, nos topamos con una amplia investigación (Calvete, Orúe, Aizpuru y Brotherton, 2015) en la que se examinó la prevalencia, características y funciones de las Autolesiones No Suicidas (ANS) entre adolescentes españoles. La 
muestra estuvo conformada por 1.864 adolescentes de edades comprendidas entre $\operatorname{los} 12$ y los 19 años (Edad media $=15,32 ; \mathrm{SD}=1,97 ; 51,45 \%$ chicas). Los participantes completaron una versión modificada del autoinforme de evaluación funcional de la automutilación (FASM) confeccionado casi veinte años atrás por Lloyd, Kelley y Hope (1997) para evaluar las tasas y métodos para autolesionarse utilizados durante el último año. El hallazgo de la replicación española de dicho estudio marca una tendencia, preocupante para la salud pública, ya que revela que: las CAL son comunes entre los adolescentes españoles. Más de la mitad de la muestra refirió tal comportamiento en el último año y el 32,2\% se había causado lesiones graves. Las funciones de las ANS autolesiones no suicidas fueron examinadas utilizando análisis factorial confirmatorio. Los resultados apoyaron un modelo jerárquico consistente en dos factores: reforzamiento automático, que explica el refuerzo automático positivo y negativo, y el reforzamiento social, que explica el refuerzo social positivo y negativo. Tales conclusiones avalan el Modelo Tetrafactorial propuesto por Nock y Prinstein (2004), dado que el "refuerzo automático" coincide con la función de beneficio intrapersonal positivo (la autolesión aporta sensaciones novedosas y excitantes que ayudan a combatir la abulia y la apatía) y de beneficio intrapersonal negativo (la autolesión alivia emociones como rabia, ira, decepción, fracaso, miedo, tristeza, soledad, abandono...), y el "reforzamiento social" se yuxtapone con los beneficios interpersonales positivos (la autolesión sirve para conseguir cuidados y atención, amor y protección), y con los beneficios interpersonales negativos (la autolesión, debido a los riesgos para la salud que conlleva, exonera al individuo de responsabilidades sociales o compromisos familiares, etc). Para ahondar en la comprobación de estas variables, disponemos de un útil instrumento adaptado por García-Mijares, Alejo-Galarza, Mayorga-Colunga, Guerrero-Herrera y Ramírez-García de Luna (2015): la versión validada en español del Self-Halm Questionnaire.

La mera investigación documental en las diversas bases de datos (Psicodoc, Psychinfo, EBSCO, Dialnet, Scielo) permite comprobar que la pesquisa científica del problema que comenzó tímidamente en 1960, se ha quintuplicado a partir de los años '90 del pasado siglo (Díaz de Neira, García-Nieto, León.Martínez, PérezFomiyana, Baca y Carballo, 2015; Ibáñez-Aguirre, 2017). Tal vez ha dejado de ser considerada una rareza o excentricidad puntual que se velaba o minimizaba, a ser juzgada como un signo precursor de riesgo suicida y un indicador alarmante de pérdida de salud mental en la población general, implicando un número de atenciones médicas y psicológicas urgentes en los centros de salud y en las urgencias hospitalarias (Belçaguy, 2012; García-Mijares, et al., 2015; Kirchner, et al, 2011; Sourander et al., 2005).

El mapa de distribución geográfica de las autolesiones en Europa sitúa a España en $5^{\circ}$ lugar de prevalencia, después de Alemania, Polonia, Reino Unido y Francia. Autores como Liddell (2006) hablan de contagio social a partir de la expansión y universalización de Internet que ha conseguido -mediante foros $\mathrm{y}$ 
chats-crear una subcultura que normaliza y estimula el comportamiento autolesivo, mostrando procedimientos de ejecución y ocultación, sugiriendo vías, incitando retos entre los jóvenes incluso de una manera letal (Faura-García, 2011). La propagación vírica del juego de "la ballena azul" es un exponente de esta realidad e incluye entre las 'pruebas', a superar por los participantes, autolesiones de diferente gravedad que van escalando hasta desembocar en el suicidio. Ya se ha cobrado más de 130 víctimas registradas en los últimos años, alguna de ellas española.

Hace poco, Doyle, Treacy y Sheridan (2015) estimaron que el 10\% de los jóvenes sin diagnosticar se autolesionaban, la mayoría de ellos -en ambos sexospor motivos ligados a las relaciones interpersonales frustrantes y al abandono o la crítica (Forns, Amador, Kirchner, Martorell, Zamini y Muro, 2004). El pasado año, se ha dado a conocer un estudio (Colino, Escudero y Blanco, 2017), elaborado a partir de una muestra española de 151 adolescentes que presentaban comorbilidad con otras patologías (TEA; TDAH), reportándose que un 37\% de los sujetos reconocían tener conductas autolesivas, siendo el $71,5 \%$ mujeres y $28,5 \%$ varones. Llama la atención la decantación femenina de estos resultados (Favazza y Conterio, 1989; Andover, Primack, Gibb, y Pepper, 2000; Llull-Carmona, et al. 2017), por lo que se podría proponer la hipótesis de que las autolesiones tienen género, aunque ratificarla o refutarla sea objeto de otras futuras investigaciones.

Los anteriores datos vienen a corroborar otros estudios previos que, a su vez, revelaban que las autolesiones alcanzaban su cénit entre los 12 y los 16 años (fenómeno de " $u$ " invertida, denominado por Frías et al., (2012), disminuyendo desde entonces a partir de los 17 años, aunque en los casos en que se prosigue con conductas autolesivas se eleva exponencialmente el riesgo suicida (Balsa-Alfonso y Naranjo-Pérez, 2012; Nock, Joiner, Gordon, Lloyd-Richardson y Prinstein, 2006;, Pérez-Zabalza, Sánchez-Muñoz, Pozueta-Villadóniga, Vicente-Palacios y Álvarez-Villechenous, 2016). Evidencias empíricas que culminan en la revisión de Llull Carmona et al. (2017) que no deja resquicio de alivio o desmentida a la preocupación sanitaria: la edad de inicio de las conductas autolesivas es entre los 10 y los 15 años, alcanzando la edad promedio a los 12, esto es: cuando los púberes encauzan su $5^{\circ}$ o $6^{\circ}$ curso de primaria. Un $21 \%$ de los adolescentes ha realizado al menos una vez prácticas autolesivas frente a un $5 \%$ de los adultos, elevándose estas cifras a $35 \%$ de los adolescentes con patologías clínicas y a un $21 \%$ de los adultos con algún ingreso psiquiátrico tras de sí.

\section{Factores causales o motivadores}

Siendo, como es, un problema multifactorial en el que se incluyen factores sociales (ambiente familiar, presión del grupo de referencia o de iguales, experiencias precoces traumáticas), factores individuales de temperamento, tales como alta reactividad a los estímulos emocionales, sensibilidad exacerbada y sobrepresencia de emociones negativas de difícil manejo, o de personalidad, tales como impulsividad, 
baja mentalización (Sánchez-Sánchez, 2017a), fuerte autoexigencia o perfeccionismo..., donde más abundantemente se ha centrado la investigación es en la desregulación emocional (Casas-Dorado, 2016; García-Bernardo, 2000; Gratz, 2007; Mikolajczac, Petrides y Hurry, 2009) y en la influencia de los iguales (sean conocidos o virtuales), así como en la búsqueda errática de soluciones al malestar interno que tropieza con esta eventual vía y la sigue sin ser muy conscientes de a dónde conduce ni de lo adictiva que es (Martínez, 2014; Ibáñez-Aguirre, 2017). En cualquier caso, para los adolescentes solo podemos aplicar modelos interactivos tanto en la comprensión como en el abordaje del trastorno, puesto que hasta los 18 años apenas es posible diagnosticar de manera firme ninguna patología y todo queda en insinuación de posibles trastornos que tal vez lleguen a cristalizar más tarde (Faura-García, 2011).

Una curiosidad importante es que, según publicó The Lancet Psychiatry Journal (agosto 2015), los adolescentes miembros de subculturas EMO o Góticas -"tribus" muy extendidas entre ellos- tienen mayor riesgo de padecer depresión y autolesionarse. Científicos de la Universidad de Glasgow entrevistaron a 1258 adolescentes autodefinidos 'góticos', de los que el 54\% se había autolesionado y el 47\% había tratado de suicidarse. No se establece una relación de causalidad entre ambas variables, sino la constancia de la vulnerabilidad, aislamiento y riesgo de exclusión que afecta a estos colectivos y que puede derivar en prácticas como la autolesión que, por sí mismas, son marginantes, silentes, y subculturales. Muy ilustrativo para toda clase de cruces de datos es el Truth Hurt (www.selfharmuk.org/).

\section{Comorbilidades}

El propio DSM V (2013) ha incluido al fin el Trastorno de Conducta Autolesiva entre el tipo de problemas que requieren más estudio, acotando la definición de autolesión a los daños en la superficie corporal que causan sangrado, hematomas o dolor, pero que se infligen con la "expectativa de que la lesión solo conllevará daño físico leve o moderado" (Molla et al., 2015, p. 52). La Asociación de Psiquiatría Americana (APA apunta como desafío para la salud mental mundial comprender el trasfondo de estas cifras alarmantes que se explicitan en la presente revisión, lo que requerirá-apoyos muestrales y estudios epidemiológicos más amplios que permitan determinar si se trata de un síntoma o de un síndrome independiente, para lo que es necesario dilucidar su comorbilidad con otros trastornos a los que frecuentemente se asocia: Trastornos de Personalidad (sobre todo el Trastorno Límite de Personalidad (TLP), del estado de ánimo (sobre todo Depresión) (Aguilera-Losada, López-López y Magán-Magán, 2017), Trastornos Disociativos, Trastornos de Espectro Autista (TEA), Trastorno General del Desarrollo (TGD), Trastornos del Control de Impulsos (TCI), Trastornos por Abuso de Sustancias (TAS), Trastornos de Conducta Alimentaria (TCA), Esquizofrenia, Trastorno de Estrés Postraumático (TEP), etc. (Ibáñez-Aguirre, 2017; Nader y Boehme, 2003; Ulloa-Flores et al. 2013). 


\section{a) Autolesión versus Suicidio}

La más obvia y necesaria distinción que urge hacer es entre autolesiones no autolíticas o no letales (Non Suicidal Self Injuries (NSSI)) o Conductas Autolesivas (CAL) y las autolesiones sin intención suicida, pero con ideación suicida. Nock, et al. (2006) establecieron correlatos entre ambos, en el caso de adolescentes, en una muestra no clínica. Por tanto: si bien autolesionarse no implica necesariamente riesgo de consumar suicidio, alrededor del $89 \%$ de los sujetos con autolesiones presentan riesgo bajo (Forti-Sampietro y Forti-Buratti, 2012), no es menos cierto que la práctica reiterada y la cronificación de este 'recurso' de afrontamiento aumenta el porcentaje de que sea de forma accidental o sea de forma experimental (buscando salidas alternativas al malestar) termine consumándose el suicidio (González-Suárez, Vasco-Hurtado y Nieto-Betancurt, 2016). En un estudio aproximativo al tema, Villarroel, Jerez y Montenegro (2013) descubrieron que entre los adolescentes vistos en consulta, alrededor de un 35\% confesaba un intento suicida en el último año. Por supuesto, poco puede saberse, con seguridad clínica, de la inmensa minoría de adolescentes que se autolesionan secretamente y no acuden a un centro clínico, ni reportan testimonios de estos comportamientos a sus médicos de cabecera o a otros servicios de salud o educativos (de ahí las aludidas definiciones de "epidemia silenciosa" o "epidemia secreta"). Puede conjeturarse que resultaría útil, de cara a su prevención, consultar y preguntar explícitamente sobre la práctica autolesiva y hallar pronosticadores tempranos de la misma en lo que cabría interpretar como una petición de ayuda y un intento de abandono de esta estrategia tan disfuncional.

En la revisión de análisis y metaanálisis realizada por Forti y Forti (2012) son, de hecho, los adolescentes más histriónicos y narcisistas quienes cometen más autolesiones $\mathrm{y}$, en cambio, quienes menos consuman suicidio. Las tormentas afectivas serían el detonante de la autolesión, sobre todo si se trata de mujeres, al tiempo que la extorsión narcisista o 'depredadora' al entorno, si se trata de varones. Parece probado que son la impulsividad y la agresividad los factores determinantes en el incremento del riesgo suicida en mayor medida que la ansiedad, por sorprendente que pueda parecer (Klonski et al., 2011). Es llamativo que mientras la vulnerabilidad emocional (tanto por su intensidad como por su labilidad) predice conductas autolesivas, no predice, en cambio, conductas autolíticas (suicidas). En un reciente trabajo (González-Suárez, et al., 2016), se alerta sobre el hecho de que entre los adolescentes que han efectuado prácticas autolesivas, andando el tiempo, el rango de riesgo suicida oscila entre el $14 \%$ al $70 \%$.

b) Cabe proponer la siguiente secuencia a modo de hipótesis cambio a primera persona plural: la ideación suicida, propicia las conductas autolesivas; éstas, temporalmente, alivian, calman y autorregulan, alejando, de paso, el riesgo suicida; pero, a la larga, la conducta autolesiva deviene un recurso ineficaz o insuficiente, en cuyo caso emergerán siempre que concurran otros factores coadyuvantes- intentos suicidas o consumación suicida como formas de alivio 
definitivo. Sería prioritario conocer en qué momento y por qué la no-intención suicida se trasforma en intención suicida (Mosquera, 2008); y, también, si es la frecuencia, la diversidad o la gravedad de las lesiones autoinfligidas, lo que mejor predice el suicidio adolescente en esta población clínica (Cornellà i Canals, 2012).

c) Autolesión versus Trastornos de la Conducta Alimentaria (TCA)

Una de las concurrencias a la que se ha prestado mayor atención es la que liga las CAL con los TCA, destacándose que coexisten en el tiempo o bien se alternan las prácticas atentatorias contra el propio cuerpo a nivel interno (bulimia, anorexia), o a nivel externo, epidérmico, cutáneo (autolesiones en la piel). Autolesiones y medidas de restricción alimentaria van de la mano en un 50\% de chicas y en un $33 \%$ de chicos, pudiendo iniciarse indistintamente por uno u otro lado, si bien parece que quienes comenzaron con CAL y 'evolucionaron' hacia trastornos alimentarios presentaban más gravedad que quienes lo hacían a la inversa, en cuanto a la previsión pronóstica de los conflictos y a su mejora psiquiátrica o terapéutica (Ernhout, Babington y Childs, 2015). La convergencia en ambos casos de sensaciones de posesión, control del cuerpo y libertad es notable (Rodríguez y Guerrero, üÿüÿ). González-Suárez, et al. (2016) registran que la imagen corporal está más dañada en adolescentes que realizan CAL, predisponiéndolas a completar al autoataque con otros trastornos alimentarios concurrentes.

d) Autolesión versus TLP

En cuanto a la comorbilidad entre las CAL y el Trastorno Límite de Personalidad (TLP) abunda en la literatura científica (Cuevas-Yust y López Pérez-Díaz, 2012; Mendoza-\& Pellicer, 2012), sobresaliendo el hecho de que el 70\% de los pacientes jóvenes que se enfilan hacia el diagnóstico adulto de TLP han llevado a cabo CAL a lo largo de la adolescencia (Casado, 2011; Casas Dorado, 2016), incluso durante la infancia (Pozueta, Vicente, Valencia, Saavedra y Coto, 2015), sobre todo si son de tipo impulsivo, presentan niveles altos de inestabilidad emocional y no recurren o encuentran fallido el soporte familiar y social (GarcíaBernardo, 2000). Mosquera (2008) destacó la volubilidad del humor, el colapso de habilidades sociales y la imprevisión de consecuencias como variables también coexistentes entre los pacientes autolesivos y los TLP adolescentes. Forti et al., (2012) destacan, de entre los cuatro subtipos de TLP (depredador, teatral, sumiso y ausente), al histriónico como el más propenso a presentar tormentas afectivas muy expresivas, dentro de cuya escenografía aparecerían las autolesiones (aunque con baja letalidad). Otros indicadores de riesgo, también ligados al TLP, son los vínculos de apego desorganizado o caótico, haber sufrido abusos físicos o sexuales (Rhodes, 2015), el consumo de sustancias y la vivencia de soledad o incomprensión por parte de los pares. La coincidencia de ambas patologías convierte probablemente las conductas autolesivas en síntoma precursor del TLP y en una señal de alerta para su prevención: "Los episodios de autolesiones se acentúan coincidiendo, entre otros, con los factores de riesgo siguientes: la crisis de identidad típica de la ado-lescencia, la baja autoestima y la confluencia de situaciones promotoras de 
estrés grave" (Ibáñez-Aguirre, 2017, p. 67).

e) Autolesión versus TDAH

Valverde-Eizaguirre y Inchauspe-Aróstegui (2014) dieron cuenta extensamente de la comorbilidad de ambas entidades clínicas, a veces certificada como accidentalidad fortuita. Más recientemente, destaca la investigación ła llevada a cabo por Colino, Escudero-Nafs y Blanco (2017) en el Hospital Puerta de Hierro de Madrid, en otoño de 2014, con una muestra de 198 pacientes, de los cuales 151 adolescentes presentaban diagnósticos de TEA, TDAH, en la que trataron de validar dos hipótesis fundamentales: si las autolesiones son entre las chicas es una opción equivalente a los videojuegos para los chicos. No solo concluyeron afirmativamente este balanceo, sino que pudieron predecir que ambas conductas distraen a chicas $\mathrm{y}$ chicos, respectivamente, de sus rumiaciones obsesivas e ideaciones suicidas, $\mathrm{y}$ en ocasiones predicen el TDAH o enmascaran patologías más severas. Hace algunos años, Pardos, Fernández-Jaén y Martín Fernández-Mayoralas (2009) destacaron la importancia del entrenamiento en habilidades sociales para reducir las manifestaciones patológicas en estos síndromes que con frecuencia concurren, aunque no necesariamente.

\section{f) Autolesión versus Estrés}

En cuanto a esta combinación de manifestaciones, se subraya la correlación negativa existente entre CAL y estrés, lo que se ha puesto de relieve al detectarse menor nivel de cortisol entre los sujetos que han recurrido a autolesionarse (Ross y Mckay, 1979; Villarroel, Jerez y Montenegro, 2013). Parece que el perfil endocrino presente en el transcurso de las autolesiones disminuye la respuesta fisiológica al estrés (Haynes, Williams, Brain y Wilson, 1995). Dicho de otro modo: los adolescentes muy estresados no se autolesionan, y los que lo hacen configuran un perfil hormonal incompatible con estrés, aunque no con ansiedad u otras psicopatologías (Schmahl, 2014). Según González-Suárez et al. (2016), no es tanto la intensidad del malestar la responsable del impulso a la respuesta autolítica, cuanto la convicción de no disponibilidad de otros recursos de afrontamiento. Por ello, se subraya el efecto 'terapéutico' que para muchos de ellos reviste la autolesión, dado que disminuye su tensión emocional y su hipervigilancia, deviniendo un recurso de afrontamiento que les induce calma y que autorregula sus estados de ánimo negativos. Éste es un factor clave para comprender la cronificación del fenómeno y su gravedad y riesgo de recidiva (Compas, Connor-Smith, Saltzman, Thomsen y Wadsworth, 2001; Glenn y Klonsky, 2013; Sánchez-Quintero y De la Vega, 2013; Suyemoto, 1998; Taboada, 2007a, 2007b).

g) Autolesión versus Síndrome de Estrés Postraumático (SEPT) por Abuso

Haber pertenecido a una familia abusiva en la niñez y adolescencia es una constante para un sinfín de expresiones psicopatológicas inmediatas y tardías, como es el caso a menudo de SEPT presentado meses o incluso años después de la experiencia traumática (Ansermet, 2015; López-Soler, 2008; Manca, 2011). Una experiencia de abuso (y de abuso sexual) contamina la construcción de la relación 
con los objetos, instala en la mente el germen de la desconfianza, exacerba la indefensión y merma las posibilidades de desarrollar un yo fuerte y seguro con capacidad de gestionar la realidad y la autonomía de las elecciones (Malacrea, 2011; Sánchez-Sánchez, 2011). Los abusos generan más 'patología de déficit' que patología de conflicto, lo que aumenta la propensión de probar fórmulas relacionales e intrapersonales de fuga y alivio de las emociones negativas. Sobre todo, si los abusos han sido reiterados, se troquela un esquema cognitivo violento, una expectativa violenta y una percepción violenta del entorno, tornando a las víctimas candidatos a la revictimización porque inadvertidamente incurrirán en decisiones y elecciones que reproduzcan los esquemas ya conocidos (Sánchez-Sánchez, 2017b). Favazza (1989) encontró que las mujeres que se autolesionan, al cabo de un tiempo, aumentan las posibilidades de desarrollar un SEPT, causado no tanto por las heridas en sí cuanto por los abusos que originariamente sufrieron. De algún modo, se sugiere que la autolesión es una 'solución' cortoplacista, mientras que el SEPT no es una solución sino una reacción expresiva del fracaso de todas las soluciones y afrontamientos previos ante el trauma (Klonsky y Moyer, 2008). López-Soler (2008) aconseja no trivializar, ni establecer conexiones precipitadas entre el maltrato o abuso infantil y sus consecuencias psicopatológicas, pues, aun tratándose de un trauma complejo, no se debe ignorar la mediación de otros factores atenuantes que actúan filtrando o frenando el desarrollo de trastornos.

Según Echeburúa y Corral (2006) y Aguilar-Cárceles (2009), el abuso induce y precipita reacciones violentas en los chicos y reacciones autodestructivas en las chicas. Pese a la raíz común, los signos delatores del abuso que esté sufriendo el adolescente pueden estar muy diferenciados según género, sobre todo si son esporádicos o continuados o extra/intrafamiliares. El abuso entre pares, sobre todo el bullying (u otras variantes actuales como el sexting o el ciberbullying) predisponen la comisión de autolesiones (Villalobos-Parra, 2013). No resulta complicado, a la luz de las investigaciones, suponer que tanto la experiencia de abuso vertical, como de abuso horizontal, detonan un sentimiento de profundo desvalimiento y que, con la mediación de elaboraciones y cristalizaciones depresivas, disociativas o límites, aparezca la autolesión como expresión fenoménica del malestar y la destrucción/desvalor interno que sienten tener. La diferencia principal estriba en que la autolesión es el desenlace que busca salir de la anestesia, la desorganización, la tensión ingobernable, mientras que el SEPT deviene la manifestación del fracaso absoluto en la autorregulación por vías más saludables (Castro, Planellas y Kirchner, 2014). Durante la ejecución de las autolesiones encontramos componentes inhibitorios (apaciguar las emociones negativas) y excitatorios (aumentar la vigilancia perceptiva, "despertar", lo que ocurre a raíz de la visión de la sangre o la tardía propiocepción dolorosa); en cambio, en el SEPT predominan los componentes excitatorios y no buscan otra autocuración o autoterapia sino a través de las $\mathrm{CAL}$, fórmula rápida y eficaz de alivio inmediato (Brown, Williams y Collins, 2007). 


\section{Significados}

Puesto que las autolesiones se infligen al cuerpo, preguntarse por el sentido de las autolesiones es hacerlo por la potencialidad escenográfica del cuerpo (Casado, 2011). El marco epistemológico que más ha resaltado este enfoque es el desarrollado por la Escuela de Psicosomática IPSO de París, desarrollada, entre otros, por Marty (1976, 1992, 1997), Smadja (1993,1995), Sánchez-Sánchez (2008) o Zubiri (2010). Desde otros enfoques, de una hermenéutica más simbólica, basada en la interpretación del sentido inconsciente de la conducta, también se contempla el cuerpo como el teatro de un drama (McDougall, 1998), o un lugar para representar las pasiones, reminiscencias (Moreau, 2003), secuelas de batallas pretéritas y las anticipaciones de la evolución personal futura (Weissberg, 2007).

¿Por qué un individuo se hace eso a sí mismo, contradiciendo el natural impulso a la supervivencia y a la autoprotección? Quizá fuera éste el lugar idóneo para invocar la pulsión de muerte que Freud introdujera en su andamiaje teórico en "Más allá del principio del placer"(1919/20), si en verdad el propósito autodestructivo fuera el dominante en las autolesiones. Sin embargo, no es la autoaniquilación, ni siquiera el ataque simbólico a partes rechazadas del self que se visualizan en un autoasesinato figurado o parcial del propio cuerpo, tampoco parece ser que en las autolesiones se dé forma a una orientación masoquista (Ghent, 2014) pues no requiere de otro que le inflija castigo, sino que víctima y victimario del daño coinciden. Muchas de estas conjeturas propias de la escasa literatura sobre autolesiones existente hasta los últimos 25 años fueron esbozadas por Menninger (1938) en "El hombre contra sí mismo". He aquí, no obstante, que, en los últimos 15 años, se ha producido una vuelta de tuerca a la hora de proveer de significado la conducta autolesiva. Suyemoto (1998) comenzó hace casi dos décadas preguntándose por las funciones sociales y el impacto de las autolesiones entre los jóvenes japoneses, a raíz del epidémico estallido de los hikikomori, antes de que se propagaran a la sociedad occidental de manera modal, como fue el caso de Colombia (Rodríguez y Guerrero, 2005), Finlandia (Laukkanen, Rissanes, Honkalampi, Kilma, Tolmunen y Hintika, 2009), Noruega (Holm y Severinsson, 2010), o México (Albores-Gallo et al., 2014), entre otros países.

Ahora las investigaciones muestrales, las encuestas, anamnesis, estudios grupales y generacionales de adolescentes que cometen autolesión, apuntan en otra dirección. Hace poco, Sánchez-Sánchez (2017a) propuso tres variantes de CAL en función de su significado: 1) las de tipo catártico (Ross y Mckay, 1979), 2) las de tipo reintegrativo (Simpson, 1980), 3) las de tipo manipulativo. De las dos primeras también habían hablado explícitamente Nader y Boehme (2003):

- En el primer caso, el propósito de las CAL es dejar fluir y drenar los conflictos que parecieran disolverse con el daño físico, disminuyendo la tensión y superando los bloqueos emocionales;

- En el segundo caso, que suele incluir a pacientes -y en mayor medida si son adolescentes- con débil o precario sentimiento del yo, disociados, 
extrañados, miméticos, despersonalizados, con disforia de identidad de género, etc, el propósito es restablecer el sentido de la propia identidad, mentalizar menos confusamente el propio yo, percatarse de sí mismos;

- En el tercer caso, el propósito es conseguir alguna ventaja, premio o recompensa del entorno: acercar a los padres, hacerse perdonar, concitar la atención de las figuras significativas, salir del aislamiento. Por ampliar esta línea, y sin que eso suponga encasillar excluyentemente a los pacientes que se autolesionan, podemos ver que ciertos perfiles emanan de los tipos enunciados:

a) el tipo alexitímico, de baja inteligencia emocional, escasamente capaz de gestionar sus conflictos, inmaduro y desmentalizado (autolesiones de tipo catártico) (Pérez-Zabalza et al., 2016; Sánchez-Sánchez, 2018).

b) el tipo confuso, lábil, desorganizado, vacío, disociado, incapaz de síntesis psíquica, intolerante a las emociones negativas (autolesiones de tipo reintegrativo) (Muñoz-Algar y Bernal-García, 2016).

c) el tipo solitario, aislado, ineficaz en la comunicación, excluido o rechazado social, con sensaciones de invisibilidad y descontento con su entorno (autolesiones de tipo manipulativo) (Villarroel et al, 2013).

No se pretende con lo anteriormente expuesto agotar o simplificar las tipologías autolesivas, sino arrojar alguna luz sobre los significados que pueden darse a estos síntomas-signos que devienen un lenguaje bizarro. El cuerpo es la pizarra sobre la que se trazan unos códigos emocionales que, como terapeutas, hemos de saber descifrar y reconducir. Por eso, ampliando la hipótesis anterior, esbozamos el ramillete de convergencias siguientes:

El marco interpretativo es doble: la teoría psicosomática de la Escuela IPSO (París) y la teoría de la mentalización, representada por Fonagy, Bateman, Lorenzini y Allison, entre otros.

a) La relación entre el primer grupo y las personalidades límite más impulsivas y empobrecidas, que utilizan un pensamiento operatorio, y que no alcanzan a representarse la tensión mental sino solo la tensión fisiológica, por lo que su sistema se asemeja al modelo hidráulico: de carga/descarga de tensión y buscan regularse mediante las autolesiones, vaciándose de un malestar que no saben tramitar y que les inunda descontrolándolos (Doctors, 2007; Fonagy y Lorenzini, 2014; LanzaCastelli, 2009).

b) La relación entre el segundo grupo y las personalidades límite más complejas con predominio de alternancias de estados del yo, de identidad difusa, con dificultad para integrar ciertos estados psíquicos como propios. La autolesión es el recurso para recuperar la conciencia del yo personal, para regresar al sí mismo que reconocen como válido y aceptable. Esta modalidad sería característica de pacientes bordeline agitados y del Trastorno Disociativo (Forti-Sampietro et al., 2012).

La relación entre el tercer grupo y las personalidades histriónicas, narcisistas 
e inmaduras. Lo que destaca en ellos es la necesidad de rescatar al 'otro' al servicio de sus fines: ocupar un lugar que sienten haber perdido, ganar prebendas en la familia o amigos, exonerarse de responsabilidades, llamar la atención de los progenitores desatentos. La autolesión cumple aquí la función de un lenguaje que se habla a través de las heridas (Hernández-Jiménez, 2010; Sánchez-Sánchez, 2017b).

\section{Perspectivas hermenéuticas de valoración-}

Para abordar los sentidos, motivos, razones, objetivos o intenciones de las CAL se han invertido cuantiosos esfuerzos de investigación. Según cuáles sean los modelos interpretativos empleados, podemos toparnos con versiones que van:

1) desde el análisis funcional de la conducta de la matriz cognitivo-conductual (Ibáñez-Aguirre, 2017), pasando por

2) modelos de la psicología analítica junguiana que recurre al concepto de 'sombra' como ciego y disociado impulso que brota de las cavernas del inconsciente,

3) modelos funcionalistas (Nock y Prinstein, 2004),

4) modelos heredados de la teoría de la comunicación (Manca, 2011; Morán, 1999),

5) modelos psicodinámicos que enfocan las autolesiones como mecanismos disfuncionales de defensa ante el descontento de sí mismos, la pérdida de autoestima e incremento de la culpa (Scilleta, 2009; Weissberg, 2007; Zubiri, 2010).

6) modelos derivados de la teoría del apego y la mentalización que cargan el acento en el fracaso en la construcción de los apegos primarios como fuente de seguridad y estabilidad, así como en la carencia de aptitud para representarse el mundo interno en términos de pensamientos y afectos (Bateman y Fonagy, 2006; Doctors, 2013; Fonagy, 2000, 2015; Fonagy y Lorenzini, 2014).

7) modelos neurobiológicos que lo abordan a partir de los mecanismos perceptivo-reactivos al dolor, la respuesta al estrés, y los sistemas dopaminérgicos y serotoninérgicos del cerebro y la respuesta endocrina a la ansiedad (Mendoza y Pellicer, 2002; Schmahl, 2014), hasta

8) modelos descriptivos mixtos, que renuncian a la interpretación escolástica de la autolesión y se limitan a registrar lo que los propios pacientes manifiestan (Klonski, 2011).

Con visiones tan comprimidas como las expuestas en el párrafo anterior, falta la precisión y el detalle necesarios para comprender el fondo de la cuestión. En aras a la justicia científica, empero, no podemos otorgar a todos los modelos enunciados el mismo valor, puesto que, tanto por la seriedad como por el número de líneas de investigación abiertas al respecto, los modelos dominantes que prevalecen en los últimos tiempos son: 
- Modelo de la expresión o lenguaje corporal: Taboada (2007a, 2007b) es abiertamente partidario de esta lectura: despoja a las autolesiones de función manipulativa o reorganizativa y destaca la intención expresiva y comunicativa. Según él, no se espera respuesta del entorno, ni cambios en él, sino que constituye una expresión de la desesperanza y la decepción que siente, de los otros y de sí mismo. La expresión sería una manera unidireccional de queja, un grito de sangre acusatorio y autoacusatorio. Rodríguez et al. (2007, p. 251) lo explicitan así: “en muchos casos de automutilación el cuerpo es usado como lugar de expresión de alguna situación que resulta innombrable y se pone en el cuerpo para conseguir ser expresada....". De parecida línea interpretativa es Pietrocola (2012), que contempla la autolesión como un lenguaje a través del cual el paciente inscribe en el cuerpo una angustia que le resulta impensable e inefable oralmente.

- Modelo de la autorregulación emocional: Este enfoque considera la autolesión una fórmula rápida, urgente, barata, que no precisa ayuda de nadie, que se puede hacer en soledad y proveé inmediata recuperación del autocontrol y la autoposesión (Rodríguez et al., 2007), detienen el displacer y ayudan momentáneamente a afrontar las contingencias más exigentes de la vida (Villarroel et al., 2013). Algunos autores subrayan la perentoriedad e inevitabilidad del acto, así como el estado crepuscular leve en que se lleva a cabo la autolesión (Nader y Boehme, 2003). Pérez-Zabalza et al. (2016), con una muestra de 101 pacientes autolesivos hallaron, cotejando varios instrumentos de medición aplicados en grupo clínico y en grupo de control, que los que se autolesionaban presentaban puntajes más elevados de disociación, alexitimia y bloqueo en la expresión de las emociones, por lo que las heridas sustituían, en cierto modo, las palabras y los otros recursos comunicativos e interactivos de los que carecían (Mikolajczac, Petrides y Hurry, 2009). La autolesión consigue situar el dolor en un lugar concreto de la piel y sacarlo de la mente, ayudando a visualizarlo y contenerlo, pudiendo actuar sobre él, lo que mitiga la impotencia y la sensación de desgobierno. En muchos casos observados por Doctors (2007), al cabo de más de 30 años de trabajar con chicas estadounidenses que se autocortan, constata que ellas dejaron de aprender y usar formas interpersonales (relacionales) de autogestión de las emociones, porque se vieron abocadas precozmente a madurar y a contar solo consigo mismas, y que desembocaron en la autolesión para regular un sentimiento de 'solo me tengo a mí misma y yo sola puedo salir de esto', cualquiera sea la dificultad que se les presente. Esto habla de antecedentes de apegos inestables, inseguros y/o desorganizados, bien sea por ausencia, negligencia u otras carencias en la relación con los cuidadores primarios.

- Modelo de los autocalmantes: Cuando la excitación inunda y deviene 
traumática, rebasando las barreras preconscientes que sirven para la protección y autodefensa del yo, la autolesión actúa como una ruptura de esclusas en una presa a punto de reventar: al liberarse parte de la tensión gracias a las heridas, magulladuras o quemaduras, el sujeto se calma y recupera una cierta organización psíquica. Killingmo (2005) explicita esta estrategia, que concuerda con la analizada antes en sus vertientes teóricas (Smadja, 1993, 1995; Szweic, 1995) o clínicas (Orozco, 2008; SánchezSánchez, 2017b) por otros autores. Mediante el dolor se halla una paradójica paz: "las partes del cuerpo agredidas equivaldrían a estados mentales que nos resultan insoportables. Atacando a esas partes del cuerpo, estamos intentando erradicar ese malestar que no podemos mentalizar" (Sánchez Quintero y De la Vega, 2013, p. 27).

Puede verse como atinada, por convergente con la idea antedicha, la expresión utilizada por Zubiri (2008) cuando resalta la función 'antihundimiento' de las conductas de autosadismo y autolesivas juzgándolas 'organizaciones de supervivencia' e incluso 'refugios en el dolor físico' temporales (Steiner, 1995). Los cortes evitan el desmoronamiento, como confiesa muy elocuentemente J. Rhodes en sus famosas memorias, editadas con el título Instrumental en 2015:

"Era perfecto. Habia encontrado algo que, aunque fuese temporal, me ayudaba a funcionar mejor, a estar más disponible, a no dejar a mi familia tirada, a ponerme la careta... Es lo que tienen las autolesiones: no solo te colocan, sino que también te permiten expresar el asco que te inspiran el mundo y tu persona, controlar el dolor, disfrutar del ritual, de las endorfinas, de esa violencia sórdida, bestial y ejercida contra uno mismo en privado, y no hacer daño a ninguna otra persona" (Rhodes, 2015, p. 125).

- Modelo de la traumatolisis: Mediante las lesiones que se inflige a sí mismo, el paciente somete a su cuerpo a purgas, castigos o padecimientos que tienen el efecto de disolver el trauma que sufrieron quizá tempranamente (Ansermet, 2015) y que no pueden tolerar, ni metabolizar en su interior. Disuelven las vivencias traumáticas psíquicas causándose un traumatismo epidérmico (Tognarelli-Guzmán, 2007). De ahí que estos pacientes califiquen sus autolesiones de "autocurativas". Merced al daño autoinfligido, despiertan del entumecimiento y adormecimiento causado por los traumas y/o abusos (Luna-Montaño, 2012). Podemos entender que, desde esta óptica, se afirme lo siguiente: "la autolesión es una solución temporal a un problema permanente" (Muñoz-Algar et al., 2016). A la par que se desplaza el trauma desde lo mental a lo físico, el sujeto logra reorganizar momentáneamente su psiquismo, evitando la psicosis. Tal es la visión de Zubiri $(2008,2010)$, quien considera que el recurso autolítico constituye una forma de autosadismo que puede resultar adictiva porque 
propicia la escapada del horror mental interno que se vive de forma egosintónica. Dicho más sencillamente: haciéndose daño esquivan la depresión o la locura. Las autolesiones emergen como una forma opcional de negociar con un trauma que no es ni representable, ni susceptible de inscribirse en la memoria biográfica sin que active un sentimiento de ser 'molecularmente malo', de estar contaminado, o en bancarrota existencial. Con un trauma se pretende mágicamente a disolver otro que no puede metabolizarse (Malacrea, 2011).

- Modelo de la búsqueda identitaria: Para las autolesiones adolescentes, no podemos ignorar el sentido de deconstrucción del modelo infantil del yo y construcción del modelo ‘evolucionado' del yo. El cuerpo infantil es un cuerpo recibido, el cuerpo adolescente empieza a ser un cuerpo electivo, configurado, separado, desprendido de las envolturas psíquicas familiares. El adolescente, máxime ante circunstancias conflictivas, necesita percibir que posee su cuerpo, que es dueño de él, que puede hacer algo con él. Su proclama autolesiva dice "me corto, luego existo". Así, puede hablarse de una suerte de desafio evolutivo apuntado por Manca (2011) y que consiste en que, a través de las autolesiones, los adolescentes se apropian de su territorio corporal y reivindican su existencia, superando alienaciones familiares o grupales de este modo. Las formas de body modification estarían en un lugar intermedio entre la autolesión que autoinflige daño y la autolesión que confiere identidad. Las heridas del branding o el microdermal (que incrusta insectos de silicona o injertos de titanio) adquieren el carácter de prótesis identitaria. Odian inspirar compasión o ser juzgados vulnerables o débiles, como descubrieron en una amplia muestra de adolescentes portugueses Xavier, Cunha y Pinto (2015), y la autolesión es tomada como el 'mejor amigo' que les facilita el camino del fortalecimiento del yo, sobre todo en situaciones tumultuosas.

- Modelo de la desmentalización: Las muy conocidas teorías de Fonagy (2000, 2015) y colaboradores (Bateman y Fonagy, 2006; Fonagy y Lorenzini, 2014) en torno al apego y la función reflexiva o mentalización brindan un modelo interpretativo adecuado para comprender que la mentalización es como "el sistema inmune de la psique, en la medida en que absorbe estresores internos y externos, excesos traumáticos y presiones internas, (...)"(Lanza-Castelli, 2013b, p. 161). Las personas autolesivas parecen no haber avanzado desde las fases prementales (equivalencia psíquica, 'como sí' - pretend mode-, y teleológica) a las mentalizadas (Lanza-Castelli, 2009, 2010, 2012, 2013a, 2013b), razón por la que probablemente ante el dolor emocional que no pueden transformar en sufrimiento mental (Ávila, 2011) incurren en: funcionamientos reactivos automáticos (en vez de controlados), en procesos afectivos de reactividad emocional (en vez de elaborados cognitivamente), en procesos 
autocentrados, aunque de forma difusa y caótica (en vez de interpersonales y relacionales), en procesos introvertidos y en 'modo autista' (en vez de extrovertir y comunicar las sensaciones que se apoderan de ellos).

El conocimiento de las dimensiones prementales elicita un patrón psicológico que nos es familiar: persona regida por dinamismos primarios y operatorios de la mente (Marty, 1976, 1992, 1997), impulsiva, introvertida, de apegos evitativos o desorganizados, desregulada en sus emociones y con procesamiento cognitivo errático, de identidad difusa o precaria, con vinculaciones inexistentes o erráticas.

\section{Prospectiva}

Para concluir, quedan sugeridas líneas de debate para el futuro:

a) Habida cuenta de la clara feminización de las autolesiones (Favazza y Conterio, 1989; Llull-Carmona et al., 2017), cabe estudiar la especial relación con el Yo-piel de las mujeres, y si las autolesiones tienen género como consecuencia de una construcción social del cuerpo femenino, o porque constituyen una escenificación de la intimidad, del secreto, de la burbuja en la que edifican su separación/individuación respecto a los objetos de relación.

b) A raíz del estudio en paralelo de los mecanismos psíquicos que cursan antes, durante y a lo largo del desarrollo de ciertas enfermedades autoinmunes, reflejo aquí la vaga sospecha de que se da una coincidencia en algunos mecanismos neurobiológicos y endocrinos entre éstas y el trastorno autolesivo. No desestimar lo obvio: ambas son vías por las que el sujeto se daña a sí mismo, sea al cuerpo funcional, sea al cuerpo expresivo, sea al cuerpo como posesión y testigo de los padecimientos no metabolizados. Tenemos la intuición de que existen coincidencias psicosomáticas en ambas manifestaciones de autoataque a la integridad y a la salud.

c) A tenor del carácter epidémico y del rango cada vez más amplio de edad que abarcan las autolesiones y que, según se evidencia hospitalariamente, comienzan a presentarse episódicamente desde los 7 años, es precisa una acción preventiva en los ámbitos escolar y de la atención primaria, elaborando protocolos que ayuden a detectar precozmente el riesgo, así como generar pautas estandarizadas (tales como el teléfono de la Asociación ANAR, cuestionarios de autolesión que se apliquen en la enseñanza secundaria (García Mijares et al., 2015; Ougrin y Boege, 2013), páginas web sanitarias que contrarresten el modelado social de contagio de estas conductas) en la línea de la prevención secundaria.

Conviene indagar acerca de las razones que convierten a las Terapias Basadas en la Mentalización (Bateman y Fonagy, 2006; Fonagy, 2014) junto con las Terapias Dialéctico-Conductuales (de origen en Linehan, 1993) las que han 
demostrado mayor eficacia en la remisión y abandono de las conductas autolesivas, por encima de cualesquiera otros modelos-(más adelante: apartado a) (terapia icónica, terapia de esquemas, terapias cognitivas de corte más tradicional, como las de Beck, terapias focalizadas en la transferencia, como las desprendidas de los modelos del psicoanálisis interpersonal de Kernberg, y por supuesto de otros modelos cotejados de terapias psicodinámicas, conductistas, sistémicas, familiares, etc), según se deduce del amplísimo barrido de estudios empíricos efectuados por Cuevas-Yust y López Pérez-Díaz (2012) y por Molla et al., (2015).

a) En dicho estudio se ha constatado que estas modalidades de terapia disminuyen significativamente el número de hospitalizaciones, la ideación suicida y los síntomas depresivos y ansiosos. Cierto que las cifras se basan en el metaanálisis de estudios seleccionados, que recaban los registros de eficacia de los participantes en los mismos, así como los modelos de intervención confesados, sin especificarse los objetivos o los métodos concretos utilizados a tal fin, quedando fuera de estos estudios los abordajes realizados desde otros enfoques teóricos, técnicos y con objetivos clínicos más allá de la reducción o desaparición de las conductas autolesivas.

Clarificando, finalmente, el sentido del titulillo "Un grito de sangre": se apela a todos aquellos terapeutas que trabajan sobre la consideración de-que la palabra-es un cauce simbólico para la expresión, la regulación, la liberación traumática y la mentalización, mucho más eficaz y manejable que los 'gritos de sangre'. Redacción más poética que directa y precisa.

\section{Referencias bibliográficas}

Aguilar-Cárceles, M. (2009). Abuso sexual en la infancia. Anales de Derecho, 27, 210-240. Recuperado de: http://revistas.um.es/analesderecho/article/view/118031/11157

Aguilera-Losada, M. P., López López, Ma C. y Magán-Magán, Mª M. (2017). El sufrimiento y la depresión que conducen al suicidio a los adolescentes. XVIII Congreso Virtual Internacional de Psiquiatría. Recuperado de: http://www.Interpsiquis.com

Albores-Gallo, L., Méndez-Gallo, J. L., Xóchitl-García Luna, A., Delgadillo-González, Y., Chávez-Flores, C. I. y Martínez, O. L (2014). Autolesiones sin intención suicida en una muestra de niños y adolescentes de la ciudad de México. Actas Españolas de Psiquiatría, 42(4), 159-168.

Andover, M. S., Primack, J. M., Gibb, B. E. y Pepper, C. M. (2000). An examination of non-suicidal self-injury in men: Do men differ from women in basic NSSI characteristics? Archives of Suicide Response, 14, 79-88.

American Psychiatric Association (2013). Manual Diagnóstico y Estadístico de los Trastornos Mentales (5 Ed.), Barcelona, España: Panamericana.

ASEFO. Autolesión Selfinjury Foro. Organización ASEFO. http://www.autolesion.com/

Ávila, A. (2011). Dolor y sufrimiento psíquicos. Clínica e Investigación relacional, 5(1), 129-145. Recuperado de: http://www.psicoterapiarelacional.es/Portals/0/eJournalCeIR/V5N1_2011/09_A_Avila_Dolor-y-Sufrimiento-Psiquicos_CeIR_V5N1.pdf

Ansermet, F. (2015). Destinos de los traumatismos precoces. Continuidades y discontinuidades del devenir. Revista de Psicoterapia y Psicosomática, 35(88)41-59.

Balsa-Alfonso, A. y Naranjo-Pérez, R. (2012). La conducta suicida: su análisis en la adolescencia. XIII Congreso Virtual de Psiquiatría.com. Recuperado de: http://www.interpsiquis.com. 
Bateman, A. y Fonagy, P. (2006). Mentalization-based treatment for bordeline personality disorder, a practical guide. Londres, UK: Oxford University Press. Version española: Tratamiento basado en la mentalización para trastornos de la personalidad. Una guía práctica. Bilbao, España: Desclée de Brouwer.

Belçaguy, M. N. (2012). Adolescentes que se autolesionan. ¿Tramitación de la angustia? En J. Barrionuevo (ed.), La angustia en la clínica con adolescentes (pp. 13-21). Buenos Aires, Argentina: Eudeba.

Brown, S., Williams, K. y Collins, A. (2007). Past and recent deliberate self-harm: emotion and coping strategy differences. Journal of Clinical Psychology, 63, 791-803. Doi:10.1002/jclp 20380

Calvete, E., Orúe, I., Aizpuru, L. y Brotherton, H. (2015). Prevalence and functions of non-suicidal self-injury in Spanish adolescents. Psicothema, 27(3), 223-228.

Casas-Dorado, A. I. (2016). Comportamiento autolesivo como herramienta de autorregulación emocional en una adolescente de 14 años. Clínica Contemporánea, 7(3), 203-220.

Casado, L. C. (2011). Los discursos del cuerpo y la experiencia del padecimiento. Acciones autolesivas corporales en jóvenes. Tesis doctoral. Tarragona, España: Universidad Rovira i Virgili.

Castro, K., Planellas, I. y Kirchner, T. (2014). Predicción de conducta autodestructuva en adolescents mediante tipologías de afrontamiento. Universitas psicológica, 13(1), 1-17. doi: 10.11144/-Javeriana. UPSY 13-1 pcaa.

Chapman, A. L., Gratz, K. L. y Brown, M. Z. (2006). Solving the puzzle of deliberate self harm: The experiential avoidance model. Behaviour Research and Therapy, 44, 371-294.

Colino, L., Escudero-Nafs, A., Blanco, R., Marín, M., González-Villalobos, I., Rodríguez-Arenas. M. A. y Salas, M.C.(2017). Autolesiones y videojuegos como mecanismos distractores de la ideación autolítica en adolescentes. Póster presentado en el XVIII Congreso Virtual de Psiquiatría.com. Recuperado de: http:// www.interpsiquis.com

Compas, B. E., Connor-Smith, J. K., Saltzman, H., Thomsen, A. H. y Wadsworth, M. F. (2001). Coping with stress during childhood and adolescence: Problems, progress, and potential in theory and research. Psychological Bulletin, 127(1), 87-127. doi: 10.1037//0033-2909 127.1.87

Cornellá i Canals, J. (octubre, 2012). Conducta autodestructiva en el adolescente. Trabajo presentado en el I Congreso Virtual Salud y Desarrollo de Adolescentes y Jóvenes. Recuperado de: https://bit.ly/2B0s91P

Cuevas-Yust, C. y López Pérez-Díaz, A. G. (2012). Intervenciones psicológicas eficaces para el tratamiento del trastorno límite de la personalidad. International. Journal of Psychological Therapy, 12(1), 97-114.

Díaz de Neira, M., García-Nieto, R., León-Martínez, V., Pérez-Fominaya, M., Baca, E. y Carballo, J. J. (2015). Prevalencias y funciones de los pensa-mientos y conductas agresivas en adolescentes. Revista de Psiquiatría y Salud Mental, 8(3), 137-145. doi: 10.1016/j.rpsm.2013.09.003

Doctors, S. (2007). Avances en la comprensión y tratamiento de la autolesión en la adolescencia. Aperturas Psicoanalíticas, 27. Recuperado de: https://bit.ly/1TWd8mh

Doctors, S. (2013). Perspectivas del apego en el trabajo clínico con adolescentes y sus figuras parentales. Clínica e Investigación relacional, 7 (2), 296-307. Recuperado de: https://bit.ly/2K9hMQu

Doyle, L., Treacy, M. P. y Sheridan, A. (2015). Self-harm in young people: Prevalence, associated factors, and helpseeking in school-going adoles-cents. International Journal of Mental Health Nursing, 24(6), 485-495. doi: 10.1111 /inm. 12144

Echeburúa, E. y Corral, P. (2006). Secuelas emocionales en víctimas de abuso sexual en la infancia. Cuadernos de medicina forense, 12(43-44), 75-82. Recuperado de: http://scielo.isciii.es/pdf/cmf/n43-44/06.pdf

Ernhout, C., Babington, P. y Child, M. (2015). ¿Cuál es la relación? Autolesión no suicida y trastornos de alimentación. The Information Brief Series, Cornell Research Program on Self-Injury and Recovery 1-4. Cornell University, Ithaca, NY. Recuperado de: https://bit.ly/2yBmbHs

Echeburúa, E, y Corral, P. (2008). Trastorno de estrés postraumático. En A. Belloch, B. Sandín, y F. Ramos (eds.), Manual de psicopatología (vol. 2) (pp.137-148). Madrid, España: McGraw-Hill.

Escobar, M. J., Santelices, M. P. y Peláez-Elizalde, G. (2013). Psicoterapia basada en la Mentalización como tratamiento para trastornos de Personalidad Bordeline. Revisión teórica de los postulados de Fonagy. Summa Psicológica Ust, 10(1), 155-160. Recuperado de: https://bit.ly/2K1HfMp

Faura-García, J. (2011, junio 05). Guía de medidas anticontagio y contra las desventajas de Internet ASeFo: Autolesión Selfinjuri Foro. Recuperado de: https://bit.ly/2txL9Bx

Favazza, A. R. y Conterio, K. (1989). Female habitual selfmutilators. Acta Psychiatryc Scandinava, 79, $283-289$. Favazza, A. R. (1998): The coming of age of self-mutilation. Journal of Nervous Mental Diseases, 186, $259-268$. Fonagy, P. (2000). Apegos patológicos y acción terapéutica. Aperturas Psicoanalíticas, 4. Recuperado de: http:/ /www.aperturas.org/articulos.php?id=0000104\&a=Apegos-patologicos-y-accion-terapeutica 
Fonagy, P. y Lorenzini, N. (2014). Apego y trastornos de la personalidad. Mentalización. Revista de Psicoanálisis y Psicoterapia, I(2).

Fonagy, P. (2015). Uso de la mentalización en el proceso psicoanalítico. Ciencias Psicológicas, 9(2), 179-196. Recuperado de:http://www.scielo.edu.uy/scielo.php?script=sci_arttext\&pid=S1688-42212015000200007

Forns, M., Amador, J. A., Kirchner, T., Martorell, B., Zamini, D. y Muro, P. (2004). Sistema de codificación y análisis diferencial de los problemas de los adolescentes. Psicothema, 16(4), 647-654.

Forti-Sampietro, L. y Forti-Buratti, M ${ }^{\mathrm{a}}$ A. (2012). Trastorno límite de la personalidad y conductas autolíticas. Revista Española de Medicina Legal, 38(4), 149-154.

Frías, A. y Vázquez, M. (2012). Conducta autolesiva en adolescentes: prevalencia, factores de riesgo y tratamiento. Cuadernos de Psicosomática y Psiquiatría de enlace, 103,33-48. Recuperado de: https://dialnet.unirioja.es/ servlet/articulo?codigo $=4393274$

García-Bernardo, E. (2000). Control de emociones e impulsos en las personalidades bordeline. Aperturas psicoanalíticas, 6. Recuperado de: https://bit.ly/2sUWU17

García-Mijares, J., Alejo-Galarza, G., Mayorga-Colunga, S., Guerrero-Herrera, L. y Ramírez-García Luna, J. (2015). Validación al español del Self-Harm Questionnaire para detección de autolesionismo en adolescentes. Salud Mental, 38(4), 287-292. Recuperado de: https://bit.ly/2toIhI3

Ghent, E. (2014). Masoquismo, sumisión y rendición. Masoquismo como perversión de la rendición. Clínica e Investigación Relacional, 8(1), 67-93. Recuperado de: https://bit.ly/2IidTUh

Glenn, C. R. y Klonsky, E. D. (2013). Nonsuicidal Self-Injury Disorder: An empirical investigation in adolescent psychiatric patients. Journal of clinical child \& adolescent Psychology, 42(4), 112. doi: 10.1080/ 15374416.2013.794699.

González-Suárez, L. F., Vasco-Hurtado, I. C. y Nieto-Betancourt, L. (2016). Revisión de la literatura sobre el papel del afrontamiento en las autolesiones no suicidas en adolescentes. Cuadernos Hispanoamericanos de Psicología, 10(1), 41-56.

Gratz, K. L. (2007). Tarjeting emotion dysregulation in the treatment of self-injury. Journal of clinical psychology: In Session, 63(11), 1091-1103.

Haines, J, Williams, C. L, Brain, K. L y Wilson, G. V. (1995) The psychophysiology of self-mutilation. Journal of Abnormal Psychology 104, 471-89.

Hernández-Jiménez, N. (2010). Reflexiones sobre marcas en la piel, Psicología Iberoamericana, 18(1), 38-46. Recuperado de:-http://www.redalyc.org/pdf/1339/133915936005.pdf

Holm, A. L. y Severinsson, E. (2010). Desire to survive emotional pain related to self-harm: A Norwegian hermeneutic study. Nursing and Helath Sciences, 12, 52-57.

Ibáñez-Aguirre, C. (2017). Claves psicopatológicas de las conductas autoagresivas en la adolescencia. Revista de Psicología Clínica con Niños y Adolescentes, 4(1), 65-70.

Kiillingmo, B. (2005). Una defensa de la afirmación en relación con los estados de afectos no mentalizados. En A. Maladesky y M. López Ozores (eds.), Psicosomática: aportes teórico-clínicos en el siglo XXI (pp. 169185). Buenos Aires, Argentina: Lugar editorial.

Kirchner, T., Ferrer, L., Forns, M. y Zanini, D. (2011). Conducta autolesiva e ideación suicida en estudiantes de Enseñanza Secundaria Obligatoria. Diferencias de género y relación con estrategias de afrontamiento. Actas Españolas de Psiquiatría, 39(4), 226-235. Recuperado de: https://bit.ly/2yDcd8y

Klonsky, E. D. y Moyer, A. (2008). Childhood sexual abuse and non-suicidal self-injury: A meta-analysis. British Journal of Psychiatry, 192, 1-5. doi:10.1192/bjp.bp.106.030650

Klonsky, E. D. (2011). Non suicidal self injury in United States adults: prevalence, sociodemographics, topography and functions. Psychology Medical, 41, 1981-1986.

Kreitman, N. y Philip, A. E. (1969). Parasuicide. British Journal of Psychiatry, 115, 746-747

Kreitman, N. (1977). Parasuicide. Nueva York, EE.UU: Wiley.

Lanza-Castelli, G. (2009). Mentalización y expresión de los afectos: Un aporte a la propuesta de Peter Fonagy, Aperturas Psicoanalíticas, 31. Recuperado de: https://bit.ly/2tnDPJI

Lanza-Castelli, G. (2010). Poner en palabras, mentalización y psicoterapia. Aperturas Psicoanalíticas, 36. Recuperado de: https://bit.ly/2MkV2KX

Lanza-Castelli, G. (2012, diciembre), La mentalización en los trastornos de la personalidad, Revista de la Asociación de Psicoterapia de la República Argentina.

Lanza-Castelli, G. (2013b). La mentalización de la afectividad: sus perturbaciones y su abordaje clínico. Temas de Psicoanálisis, 5. Recuperado de https://bit.ly/2Kgn1Od 
Laukkanen, E., Rissanen, M. L., Hontalampi, K., Kilma, J., Tolmunen, T. y Hitikka, J. (2009). The prevalence of selfcutting and other self-harm among 13 to 18 year old Finnish adolescents. Social Psychiatry and Psychiatric Epidemiology, 44, 23-28.

Liddell, S. (mayo, 2016). La epidemia secreta de la autolesión. Kindsein magazine. Recuperado de: http:// www.kindsein.com/es/10/psiquiatria/276/

Linehan, M. (1993). Manual de tratamiento de los trastornos de personalidad límite. Barcelona, España: Paidós.

Lloyd, E. E., Kelley, M. L. y Hope, T. (1997). Self mutilation in a community simple of adolescents: Descriptive characteristics and provisional prevalence rates. Annual meeting of the Society for Behavioral Medicina, $n^{\circ}$ April. New Orleans.

Llull-Carmona, J., Francés-Sanjuán, N., Pascual-Calatayud, C., Roselló-Miranda, R., Morant-Luján, Y. y Ibáñez Soriano, E. (2017). Conductas autolesivas no suicidas: breve revisión. Conceptualización clínica y causas. XVIII Congreso Virtual Internacional de Psiquiatría. Recuperado de: http://www.interpsiquis.com

López-Soler, C. (2008). Las reacciones postraumáticas en la infancia y adolescencia maltratada: el trauma complejo. Revista de Psicopatología y Psicología Clínica, 13(3), 159-174.

Luna-Montaño, I. (2012). Transgresiones corporales, autolesión impulsiva y Psiquiatría. XIII Congreso Virtual Internacional de Psiquiatría. Recuperado de: https://bit.ly/2yDxsHc

Malacrea, M. (2011). Trauma y reparación. El tratamiento del abuso sexual en la infancia. Madrid, España: Paidós

Manca, M. (2011). Agresiones al cuerpo en la adolescencia. ¿Redefinición de los límites del cuerpo o desafío evolutivo? Psicoanálisis, XXXIII(1), 77-88. Recuperado de: https://bit.ly/2smQs4c

Martínez, D. V. (2014). Autolesiones deliberadas. Entre la restricción y el alivio. VERTEX Revista Argentina de Psiquiatría, $X X V, 213-219$.

Marty, P. (1976). El orden psicosomático. Valencia, España: Promolibro, 1995 (1ª edición española).

Marty, P. (1992). Los movimientos individuales de vida y de muerte. Buenos Aires, Argentina: Amorrortu.

Marty, P. (1997). Mentalización y Psicosomática. Revista de Psicoterapia y Psicosomática, 37.

McDougall, J. (1998). Del cuerpo hablante al cuerpo hablado. En J. McDougall (ed.), Las mil y una caras de eros (pp. 201-223). Barcelona, España: Paidós.

Mendoza, Y. y Pellicer, F. (2002). Percepción del dolor en el síndrome del comportamiento autolesivo. Salud Mental, 25(4), 10-16. Recuperado de: http://www.medigraphic.com/pdfs/salmen/sam-2002/sam024b.pdf

Menninger, K. (1938/1972). El hombre contra sí mismo. Barcelona, España: Península.

Mikolajczac, M., Petrides, K. V. y Hurry, J. (2009). Adolescents choosing self harm as an emotion regulation strategy: The protective role of trait emotional Intelligence. British Journal of Clinical Psychology, 48(2), 181-193.

Molla, L., Batlle-Vila, S., Treen, D., López, J., Sanz, N., Martín, L.M., Pérez, V. y Bullbena, A. (2015). Autolesiones no suicidas en adolescentes: revisión de los tratamientos psicológicos. Revista de Psicopatología y Psicología Clínica, 20(1), 51-61.

Morán, C. (1999). Conductas autolesivas. En M. A. Verdugo (ed.), Hacia una nueva comprensión de la discapacidad (pp. 755-764). Salamanca, España: Amarú.

Morgan, H. G. (1979). Death wishes? The understanding and management of deliberate self harm. London, UK: Wiley.

Moreau, F. (2003). Del cuerpo biológico al cuerpo pensante: Mentalización, desmentalización, rementalización. Intersubjetivo, 5(2), 209-220.

Mosquera, D. (2008). La autolesión: el lenguaje del dolor. Madrid, España: Pléyades.

Muñoz-Algar, M. J. y Bernal-García, P. (2016). Autolesiones como respuesta, Póster presentado al XVII Congreso Virtual Internacional de Psiquiatría. Recuperado de: http://www.Interpsiquis.com

Nader, A. y Boehme, V. (2003). Automutilación: ¿Síntoma o Síndrome?, Boletín de la Sociedad de Psiquiatría y Neurología de la Infancia y la Adolescencia, 14(1), 32-37. Recuperado de: https://bit.ly/2Im2yTj

Nock, M. K. y Prinstein, M. J. (2004). A functional approach to the assesment of self mutilative-behavior.-Journal of Consulting and Clinical Psychology, 72, 885-890.

Nock, M. K., Joiner, T. E., Gordon, K. H., Lloyd-Richardson, E. y Prnstein, M. J. (2006). Non suicidal self-injury among adolescents: diagnostic correlates and relation to suicide attempts. Psychiatry Research, 144, 65-72.

Organización Mundial de la Salud (OMS) (1992). CIE-10. Trastornos mentales y del comportamiento. Madrid, España: Meditor.

Orozco, E. (2008). El papel de la libido en la autoagresión y el masoquismo. Revista de Psicoanálisis de la APM, $55,61-76$

Ougrin, D. y Boege, L. (2013). Brief report: the Self Harm Questionnaire: a new tool designed to improve identification of self harm in adolescents. Journal of adolescence, 36(1), 32-37. 
Paula, I. y Artigas, J. (2016). Vulnerabilidad a la autolesión en el autismo. Revista de Neurología, 62(1), 27-32.

Pardos, A., Fernández-Jaén A. y Martín Fernández-Mayoralas D. (2009). Habilidades sociales en el trastorno por déficit de atención/hiperactividad. Revista de Neurología 48(S02).

Pellegrini, R. (marzo, 2016). Conductas autolesivas: la agresión hacia el propio cuerpo. El cisne digital.

Pérez-Zabalza, A., Sánchez-Muñoz, B., Pozueta-Villadóniga, S., Vicente-Palacios, C. y Álvarez-Villechenous, M. (2016). Factores implicados en la Autolesión no suicida (NSSI: Non-Suicidal Self Injury), Póster presentado al XVII Congreso Virtual Internacional de Psiquiatría. Recuperado de: http://www.Interpsiquis.com

Pietrocola, A. (2012). Agresiones al cuerpo en la adolescencia. Aperturas psicoanalíticas, 41. Recuperado de: http://www.aperturas.org/articulos.php?id=0000748\&a=Las-agresiones-al-cuerpo-en-la-adolescencia

Pozueta-Villadóniga, S., Vicente Palacios, C., Valencia Agudo, F., Saavedra Rionda, I. y Coto Lesmes. I. (2015). Autolesiones en la infancia. Ilustración a través de dos casos clínicos. Servicio de Salud del Principado de Asturias.

Ramachandrán, V. S. (2012). Lo que el cerebro nos dice. Los misterios de la mente humana al descubierto. Barcelona, España: Paidós.

Rhodes, J. (2015). Instrumental. Memorias de música, medicina y locura. Barcelona, España: Blackie Books.

Rodríguez, M. y Guerrero, E. (2005). Frecuencia y fenomenología de comportamientos de daño autoinfligido sin intencionalidad suicida en pacientes colombianos con TCA. Revista Colombiana de Psiquiatría, 34(3), 343354.

Rodríguez, M., Gempeler, J., Pérez, V., Solano, S, Meluk, A. y Guerrero, E. (2007). Entre el sufrimiento interno y las palabras silenciadas. Revista Colombiana de Psiquiatría, 36(2), 237-254. Recuperado de: http://www.scielo.org.co/pdf/rcp/v36n2/v36n2a07.pdf

Rodríguez-Pulido, F. y Delgado-Bueno, S. (1994). Autolesiones deliberadas en psiquiatría forense. En S. Delgado y J. M. Maza (coords.), Psiquiatría legal y forense (pp. 1165-1210). Madrid, España: Codex.

Rodríguez-Pulido, F. y González de Rivera, J. L. (2003). Evaluación y medición del riesgo de autolesión y suicidio. En A. Bulbena Vilarrasa, G. E. Berrios y P. Fernández de Larrinoa Palacios (eds.), Medición clínica en Psiquiatría y Psicología (pp. 225-239), Barcelona, España: Masson.

Ross, R. R. y McKay, H. B. (1979). Self-mutilation. Lexington, MA: DC Health and Company.

Sanders, C. (2008). Customizing the body: the art and culture of tattooing. Philadelphia, PA: Temple University Press.

Sánchez-Quintero, S. y De la Vega, I. (2013). Introducción al tratamiento basado en la mentalización para el trastorno límite de la personalidad. Acción Psicológica, 10(1), 21-32. Recuperado de: https://bit.ly/2Kf9TFS

Sánchez-Sánchez, T. (2008). ¿Qué es la Psicosomática? Del silencio de las emociones a la enfermedad. Madrid, España: Biblioteca Nueva.

Sánchez-Sánchez, T. (2011). Del traumatismo al trauma: Desorganización y resiliencia en la elaboración postraumática. Anuario FEAP. Publicaciones de Psicoterapia en lengua española, 1-23.

Sánchez-Sánchez, T. (2017a). Autolesión y Mentalización. Viaje a través de las heridas. Clínica e Investigación Relacional, 11(2), 337-351. doi: 10.21110/19882939.2017.110208

Sánchez-Sánchez, T. (2017b). Procedimientos autocalmantes y prementalización en las autolesiones reflejadas en Instrumental de James Rhodes. Revista de Psicopatología y Salud Mental del Niño y del Adolescente, 29, 101-112.

Sánchez-Sánchez, T. (2018). La autolesión como vía de autorregulación emocional en personas con déficit de mentalización. XIX Congreso Virtual Internacional de Psiquiatría. Recuperado de: http:// www.interpsiquis.com

Schmahl, C. (2014). Bases neuronales de la autolesión. Mente y Cerebro, 66, 58-63.

Scilleta, D. (2009). Autolesiones mediante cortes reiterados en la piel. Subjetividady Procesos cognitivos, 13, 183197.

Simpson, M. (1980). The many faces of suicide. Nueva York, NY: Mc-GrawHill.

Smadja, C. (1993). A propósito de los procedimientos autocalmantes del Yo. Revue Française de Psychanalyse, 4. En C. Smadja (2005) (ed.), La vida operatoria (pp.-199-216). Madrid, España: Biblioteca Nueva.

Smadja, C. (1995). Los autocalmantes o el destino inacabado del sadomasoquismo. Revue Française de Psychanalyse, 8. En C. Smadja (2005), La vida operatoria: estudios psicoanalíticos (pp. 216-228). Madrid, España: Biblioteca Nueva.

Steiner, J. (1995). Refugios psíquicos. Organizaciones patológicas en pacientes psicóticos, neuróticos y fronterizos. Madrid, España: Biblioteca Nueva. 
Sourander, A., Aromaa, M., Pihlakoski, L., Haavisto, A., Rautava, P., Helenius, H. y Sillanpää, M. (2005). Los pronosticadores tempranos de la autolesión deliberada en adolescentes. Un estudio de seguimiento prospectivo en edades de 3 y de 15 años. Journal of Affective Disorders, 93(1), 87-96.

Suyemoto, K. L. (1998). The functions of self-mutilation. Clinic Psychology Revue, 18(5), 531-554.

Szweic, G. (1995). La utilización autocalmante del peligro y del terror. Revista de Psicoanálisis de la APM, 22, $167-$ 187.

Taboada, E. (2007a). Autolesiones (primera parte). Revista de Psiquiatría Forense y Sexología, Praxis, 5(3), 7-31. Recuperado de: https://bit.ly/2K211ro

Taboada, E. (2007b). Autolesiones (segunda parte). Revista de Psiquiatría Forense y Sexología, Praxis, 5(4), 625. Recuperado de: https://es.scribd.com/document/138251607/AUTOLESIONES

Tognarelli-Guzmán, A. (2007). Consecuencias del déficit en la mentalización del trauma. Summa Psicológica, 4(1), 1-20.

Ulloa-Flores, R., Contreras Hernández, C., Paniagua Navarrete, K. y Victoria Figueroa, G. (2013). Frecuencia de autolesiones y características clínicas asociadas en adolescentes que acudieron a un hospital psiquiátrico infantil. Salud Mental, 36(5), 417-420. Recuperado de: https://bit.ly/2IglSlL

Valverde-Eizaguirre, M. A. y Inchauspe-Aróstegui, J. A. (2014). Peculiaridades del consentimiento informado en Salud Mental. Considerando el caso TDA/H como ejemplo. Clínica Contemporánea, 5(2), 113-136.

Villalobos-Parra, L. (2013). "Bullying" como posible factor de riesgo de conductas autolesivas o suicidas en víctimas infantiles y adolescentes (Tesis de máster, Universidad de Costa Rica, San José, Costa Rica). Recuperado de: http://www.binasss.sa.cr/bibliotecas/bhp/textos/tesis47.pdf

Villarroel, J., Jerez, S. y Montenegro, M. A. (2013). Conductas autolesivas no suicidas en la práctica clínica. Primera parte: conceptualización y diagnóstico. Revista chilena de Neuropsiquiatría, 51(1), 38-45. Recuperado de: http://www.scielo.cl/scielo.php?script=sci_arttext\&pid=S0717-92272013000100006

Weissberg, K. (2007). Los caminos del dolor. Reflexiones psicoanalíticas. México: Círculo Psicoanalítico México.

Xavier, A., Cunha, M. y Pinto Gouveia, J. (2015). Autolesión deliberada en la adolescencia: el impacto de experiencias en la niñez, el afecto negativo y los temores de compasión. Revista de Psicopatología y psicología clínica, 20(1), 41-49.

Zubiri, M. (2008). Masoquismo y Autosadismo, Revista de Psicoanálisis de la Asociación Psicoanalítica de Madrid, 55, 77-90.

Zubiri, M. (2010). La falla de la organización melancólica: la adicción al dolor físico y otras formas. Revista de Psicoanálisis de la APM, 59, 145-156. 